\title{
Potência anaeróbica e capacidade Vital de alunos Aymara em duas situações GEOGRÁFICAS DIFERENTES
}

Jorge Díaz Gamboa' jediaz@uta.cl

doi:10.3900/fpi.8.3.164.p

Gamboa JD. Potência anaeróbica e capacidade vital de alunos Aymara em duas situações geográficas diferentes. Fit Perf J. 2009 maijun;8(3): 164-73.

\section{RESUMO}

Introdução: $\bigcirc$ presente estudo corresponde a uma investigação de desenho descritivo, transversal e comparativo para um grupo independente, com duas avaliações de teste e reteste em níveis de altitude diferentes (variável ambiental). Materiais e Métodos: Trabalhou-se com uma amostra probabilística, utilizando-se o método de amostra simples ao acaso da população respectiva, com 15 alunos homens da etnia Aymara, com idades de 12 a 15 anos, nascidos no planalto, e com mais de três anos de residência estável no povoado de Putre - Chile, localizado acima de 3.000 m de altura sobre o nível do mar. Resultados: Os resultados mostram que os alunos que habitam grandes altitudes apresentam uma melhoria evidente nos seus rendimentos ao nível de mar, associando-se positivamente nos rendimentos físico e fisiológico alcançados na capacidade vital, na potência anaeróbica e na produção de lactato no sangue. No entanto, estas diferenças não são significativas. Discussão: Os resultados obtidos nas variáveis medidas em relação às hipóteses colocadas ao início do estudo nos confirmam que as crianças que habitam grandes altitudes melhoram o nível de sua capacidade vital ao ser medido ao nível de mar. No entanto, apesar desta melhoria na sua capacidade vital, estas crianças só apresentam um aumento de 3,54\% na sua potência anaeróbica ao serem avaliadas ao nível de mar, o que não é significativo $(p>0,05)$, produzindo-se neste caso uma associação muito débil entre a melhoria da capacidade vital e a potência anaeróbica. A evidência estatística baseada no teste " $t$ ", onde a média e os alunos de Putre não aumentam significativamente sua potência anaeróbica quando se transladam para o nível do mar. No entanto, diminuem significativamente seu nível de lactato no sangue.

\section{PALAVRAS-CHAVE}

Grupos Étnicos, Capacidade Vital, Altitude.

\footnotetext{
1 Universidad Tarapacá de Arica - UTA - Arica - Chile
}

Copyright@ 2009 por Colégio Brasileiro de Atividade Física, Saúde e Esporte

Fit Perf J | Rio de Janeiro | 8 | 3 | 164-173 | mai/jun 2009 
Anaerobic power and Vital CAPACity of Aymara students in two different geographical situations

\section{ABSTRACT}

Introduction: This study corresponds to an investigation from descriptive, transversal and comparative design for an independent group, with two evaluations of test and retest on different levels of altitude (environmental variable). Materials and Methods: It was worked with a probability sample, using the method of simple random sample of the population, with 15 male students from the Aymara ethnicity, aged 12 to 15 years-old, born on the plateau, and with over three years of stable residence in the village of Putre - Chile, located above 3,000m of height above sea level. Results: The results show that the students who live in high altitudes show an obvious improvement in their performance at sea level, involving a positive performance in physical and physiological reached in vital capacity, in anaerobic power and in the production of lactate in blood. However, these differences are not significant. Discussion: The results obtained in the measured variables in relation to the assumptions made in the beginning of the study confirm that children who inhabit high altitudes improve the level of their vital capacity when measured at sea level. However, despite this improvement in their vital capacity, these children only show an increase of $3.54 \%$ on their anaerobic power when evaluated at sea level, which is not significant $(p>0.05)$, resulting in this case in a very weak association between the improvement of vital capacity and anaerobic power. The statistical evidence based on the " $\mathrm{t}$ " test, where the average and the students of Putre did not significantly increase their anaerobic power when moved to sea level. However, significantly reduced their level of lactate in blood.

\section{KEYWORDS}

Ethnic Groups, Vital Capacity, Altitude.

\section{Potencia anaerobica y Capacidad vital de alumnos de Aymara en dos situaciones geográficas diferentes RESUMEN}

Introducción: El presente estudio corresponde a una investigación de diseño descriptivo, transversal y comparativo para un grupos independiente, con dos evaluaciones de test y retest a niveles de altitud diferente (variable ambiental). Materiales y Métodos: Se trabajó con un muestra probabilística, utilizándose el método de muestra simple al azar de la población respectiva, la cual incluyó 15, alumnos hombres de etnia Aymara (con ambos apellidos Aymara), en edades de 12 a 15 años, nacidos en el altiplano y con más de tres años de residencia estable en el poblado de Putre, ubicados por encima de los $3.000 \mathrm{~m}$ de altura sobre el nivel del mar. Resultados: Los resultados muestran que los alumnos que habitan en la altitud, presentan una mejoría evidente en sus rendimientos a nivel de mar y se asocian positivamente en los rendimientos físico y fisiológico, alcanzados en la capacidad vital, la potencia anaeróbica y la producción de lactato en sangre. No obstante, estas diferencias no son significativas. Discusión: Los resultados obtenidos en las variables medidas en relación a las hipótesis planteadas al inicio del estudio nos confirman que los niños que habitan en la altura, mejoran el nivel de su capacidad vital, al ser medios a nivel de mar. Sin embargo, a pesar de esta mejoría en su Capacidad Vital, estos niños solo presentan un aumento del 3,54 \% en su potencia anaeróbica al ser evaluados a nivel de mar lo que no es significativo ( $p>0,05$ ). Produciéndose en este caso una asociación muy débil entre la mejoría de la Capacidad Vital y la Potencia Anaeróbica. La evidencia estadística, basada en el test " $t$ ", test que, en media, los alumnos de Putre, no aumentarían significativamente su potencia anaeróbica cuando se trasladan a nivel del mar. Sin embargo disminuyen significativamente su nivel de lactato en la sangre.

\section{PALABRAS CLAVE}

Grupos Étnicos, Capacidad Vital, Altitud.

\section{INTRODUÇÃO}

Com relação ao presente estudo, pode-se manifestar que os componentes da aptidão física se veem debilitados ou melhorados, tanto por influência do meio ambiente como por fatores genéticos, o que, de uma forma ou de outra, condicionam a que o organismo humano obtenha certas adequações biofisiológicas e estruturais que the permitam viver em zonas hipóxicas sem problemas. Em estudos realizados por Kyu Aymedov, citado por Platonov \& Bulatova ${ }^{1}$, se observou que os habitantes nativos de grandes altitudes alcançam, como média, uma diferença de $9 \mathrm{~cm}$ no seu perímetro torácico entre uma inspiração forçada máxima e uma expiração máxima. Em contraposição, nos residentes no nível do mar esta diferença não ultrapassa $7,5 \mathrm{~cm}$. Da mesma forma, estudos realizados por Reynafaye, citado por Platonov \& Bulatova ${ }^{1}$, demonstraram que os habitantes de altitude possuem maior volume e perímetro torácico do que seus similares no nível do mar. Além disso, se observou um maior conteúdo de hemoglobina, acompanhado de uma elevada atividade mitocondrial. Similares resultados foram comunicados por Saltolaya 
et al. ${ }^{2}$, em estudos realizados no norte do Chile, no planalto das Regiões de Tarapacá e Antofagasta, em assentamentos humanos localizados em diferentes níveis de altitude (Isluga $3.659 \mathrm{~m}$, Colchane $3.650 \mathrm{~m}$, Sacaire $3.450 \mathrm{~m}$, Caspana $3.260 \mathrm{~m}$ e Ollague $3.818 \mathrm{~m}$ ). A isto se soma o que foi afirmado por Astrand ${ }^{3}$, no sentido de que estas capacidades adaptativas se veem refletidas em uma leve aceleração da frequência respiratória; aumento da ventilação pulmonar e aumento do volume restante de ar, por meio da quantidade de alvéolos pulmonares; acumulação aumentada do sangue nos capilares pulmonares; crescimento da capacidade de difusão dos pulmões. Isto se reflete em um volume e perímetro de tórax consideravelmente aumentado, o que favorece sua capacidade de trabalho em meios hipóxicos, o qual está relacionado com uma grande potência aeróbica e anaeróbica ao descer ao nível do mar.

Com respeito a isto, são conhecidos os resultados esportivos alcançado em nível internacional por esportistas residentes em zonas geográficas acima de $2.000 \mathrm{~m}$ de altitude, que demonstraram possuir certos atributos ou capacidades biofisiológicas que Ihes permitem atuar ao nível do mar com sucesso, em esportes que requerem grande capacidade aeróbica (marchadores mexicanos, equatorianos e bolivianos; fundistas da Tanzânia e Quênia; entre outros). Da numerosa população que habita acima dos $3.000 \mathrm{~m}$ sobre o nível do mar, a maior percentagem mundial se acha nas cidades ou povoados do continente sulamericano, encravados na Cordilheira dos Andes, cuja população infantil deve fazer frente a este ambiente hipóxico. Esta qualidade permite que o habitante nativo, residente permanente da altitude, conte com um perfeito equilíbrio fisiológico, apesar da hipoxia ambiental resultante da baixa pressão barométrica, da baixa temperatura e do ressecamento do ambiente, características predominantes do clima altiplano durante a maior parte do ano, desenvolvendo com isso capacidades, como: maior transporte de oxigênio; maior capacidade vital; e maior capacidade de consumo máximo de oxigênio $\left(\mathrm{VO}_{2 \text { máx }}\right)$.

No caso das crianças, recentemente se demonstrou que sua permanente exposição à hipóxia em alturas maiores que $3.000 \mathrm{~m}$ mostram uma forma de adaptação fenotípica. Nestas crianças, que nascem e se desenvolvem em zonas de altitude, ocorre um aumento da ventilação pulmonar, da eficiência pulmonar e da difusão alvéolocapilar. Os volumes, tanto dos pulmões como do tórax, são maiores. Além disso, se aprecia um aumento da concentração de hemoglobina e da viscosidade sanguínea.

A adaptação em nível genético é a adaptação em sentido estrito, fruto de uma seleção natural irreversível. As características genéticas destas povoações (Sherpas do Tibete, Aymaras e Cunzas no planalto boliviano) Ihes permitem a sobrevivência na altura e persistem, mesmo que o indivíduo mude para um ambiente a alturas inferiores.

Fellmann et al. ${ }^{4}$ manifesta que a altitude de $3.627 \mathrm{~m}$ sobre o nível do mar, existente em La Paz - Bolívia, não altera a atuação aeróbica em um teste de forçavelocidade (de 6 a 10W. $\mathrm{kg}^{-1}$ ) entre as idades de 7 e 15 anos, mas reduz entre $14 \%$ e $17 \%$ o poder aeróbico desenvolvido durante um teste de 30s (teste Wingate). Esta diminuição pode dever-se a uma baixa participação da glicólise e do metabolismo anaeróbico durante este teste.

Por outro lado, o exercício em condições de hipóxia conduz a um aumento da produção de ácido láctico em comparação com o mesmo exercício executado em condições de normoxia. No entanto, depois da aclimatação à altitude, a produção de ácido láctico se atenua marcadamente, tanto no músculo como no sangue. Este fenômeno foi denominado o "paradoxo do lactato", e se sugeriu que é um fenômeno generalizado, comum a muitas formas de adaptação à hipóxia. Propuseram-se vários mecanismos para tentar explicar este fenômeno: 1) diminuição do fluxo glicolítico; 2) diminuição da reservas de glicogênio; 3) mudanças na capacidade de buffering; 4) mudanças na eficácia da contração muscular; e 5) melhora no acoplamento entre fosforilação oxidativa e fluxo glicolítico. Apesar disto, a causa deste paradoxo em sujeitos aclimados está longe de ser esclarecida.

Os estudos realizados com as crianças sobre o metabolismo anaeróbico comprovaram que existe estreita relação entre a capacidade de produzir ácido láctico e o amadurecimento sexual. A capacidade das crianças de trabalhar em forma anaeróbica é sensivelmente menor que a dos adolescentes e a dos adultos. Por exemplo, a potência anaeróbica gerada por um menino de 8 anos é $70 \%$ da que pode gerar um de 11 anos. Isto se fundamenta em uma série de características bioquímicas, nas quais se destacam um menor nível de reservas de glicogênio e, fundamentalmente, uma menor capacidade enzimática glicolítica ( PPK, PDH, LDH ).

Entre os poucos estudos realizados sobre o desenvolvimento do sistema anaeróbico em crianças e adolescentes se encontram as investigações realizadas por Bar-Or, que assinala que a capacidade anaeróbica absoluta de um menino de 8 anos é de $45 \%$ a $50 \%$ do valor de um menino de 14 anos, enquanto a capacidade relativa está próximo de 65\%-70\%.

Blimkie et al. ${ }^{\mathbf{5}}$ mediram a potência anaeróbica de crianças, utilizando o teste de Wingate, em watts. $\mathrm{kg}^{-1}$. Destes estudos se obtiveram os resultados da Tabela 1. 
Isto nos permite corroborar que, tanto o menino como o jovem têm uma capacidade glicolítica menor, ou seja, que se adapta menos aos trabalhos anaeróbicos. A tolerância à acidose aumenta durante a idade, aproximadamente 0,01 a 0,02 unidades de $\mathrm{pH}$ por ano de crescimento 6 .

\section{A Potência Anaeróbica}

A potência anaeróbica é a capacidade que o organismo humano tem para obter energia durante a realização de atividades físicas de curta duração (até $3 \mathrm{~min}$ ) e de alta intensidade, com uma frequência cardíaca aproximada entre 170 e 220 pulsações por minuto.

A produção de potência anaeróbica se encontra limitada pela taxa que a energia é entregue (produção de ATP) para a contração muscular (utilização do ATP), isto é, corresponde à taxa a qual os miofilamentos podem transformar a energia química em trabalho mecânico ${ }^{7}$. A obtenção desta energia se alcança através de dois sistemas: o metabolismo anaeróbico aláctico (sistema ATP-CP) e o metabolismo anaeróbico láctico (Glucólise anaeróbica), o que determina a capacidade anaeróbica alática e a capacidade anaeróbica lática, respectivamente.

Praagh ${ }^{7}$ define a potência muscular anaeróbica como "o maior trabalho mecânico que pode ser produzido durante exercícios de até 30s de duração", e acrescenta que o período de tempo utilizado depende da força ou da carga de trabalho que o sujeito tem que vencer e a organização da aceleração a realizar.

\section{Capacidade vital}

A capacidade vital (CV) é a quantidade máxima de ar que pode se espirar forçadamente desde os pulmões, depois de uma inspiração máxima. Ela corresponde ao volume de ar mobilizado em uma inspiração máxima por uma expi-

Tabela 1 - Potência anaeróbica em crianças de 8,0 a 17,5 anos

\begin{tabular}{lcc}
\hline idade (anos) & homens $\left(\mathrm{W} \cdot \mathrm{kg}^{-1}\right)$ & mulheres $\left(\mathrm{W} \cdot \mathrm{kg}^{-1}\right)$ \\
\hline 8,0 & 6,75 & 5,90 \\
9,0 & 7,40 & 6,90 \\
10,0 & 8,00 & 7,85 \\
11,0 & 9,00 & 9,25 \\
12,0 & 9,25 & 8,30 \\
13,0 & 9,60 & 8,30 \\
14,0 & 9,90 & 9,00 \\
14,5 & 10,59 & 8,13 \\
15,5 & 11,20 & 9,44 \\
16,5 & 11,36 & 10,37 \\
17,5 & 10,15 & 10,35 \\
18,5 & 12,54 & 9,85 \\
\hline
\end{tabular}

ração máxima, isto alcança aproximadamente $6 \mathrm{~L}$, o qual pode ser maior ou menor dependendo principalmente do tamanho do tórax, da idade e do sexo. Além disso, cabe assinalar que tem uma boa correlação com a capacidade aeróbica do sujeito ${ }^{8}$.

Estudos realizados por Fisher et al. ${ }^{9}$ sobre o prognóstico de volumes e capacidades pulmonares, se baseia na equação de regressão proposta por Baldwin (1986), citado por Martínez et al. ${ }^{10}$, que, através dela, prevê a capacidade vital de um indivíduo:

Homens: $C V=[27,63-(0,112 \times$ idade $)] \times$ estatura Mulheres: $C V=[21,78-(0,101 \times$ idade $)] \times$ estatura

A idade é utilizada em anos e a estatura em $\mathrm{cm}$. $\bigcirc$ resultado final é expresso em $\mathrm{mL}$.

Como se pode ver, existem grandes quantidades de pesquisas e conhecimentos sobre os problemas e benefícios que enfrentam as pessoas que são expostas em uma zona de altitude por períodos de tempo definidos. Porém, muito pouco se conhece sobre o que acontece no seu rendimento físico e fisiológico quando residentes de altitude descem ao nível do mar.

No Chile existem várias cidades, povos e comunidades que se situam acima de $2.000 \mathrm{~m}$, onde habitam diferentes tipos de etnia, principalmente indo-americano. No entanto, na Primeira e Segunda Regiões, estas altitudes se encontram povoadas por grupos étnicos milenares, descendentes de Atacameños, Cunzas, Collas e Aymaras, sendo estes últimos os de maior população, alcançando 48.501 habitantes, dos quais $83,91 \%$ se encontram na Região de Tarapacá, e especialmente na Comuna do Planalto de Parinacota, localizada acima de $3.000 \mathrm{~m}$, onde se concentra $15,23 \%$ da população deste povoado. A que apresenta maior densidade é Putre, situado a $156 \mathrm{~km}$ de Arica e a $3.450 \mathrm{~m}$ de altitude, concentrando $2,46 \%$ da população, equivalente a 1.005 habitantes, dos quais 22\% correspondem a crianças em idade escolar.

Portanto, tendo uma população de origem de planalto, com características biofisiológicas de adaptação em zonas de altitude, nos dá a oportunidade de obter alguma informação sobre o comportamento destas qualidades adaptativas, em zonas de nível de mar. Por tal motivo se colocou este estudo empírico, com o qual se pretende responder dúvidas, como:

a)Qual é o nível de desenvolvimento da potência anaeróbica, o nível de lactato no sangue e a capacidade vital dos alunos de Aymara em idades de 12 a 15 anos, residentes acima dos $3.000 \mathrm{~m}$ de altitude?

b) Existem diferenças no rendimento da potência anaeróbica, o nível de lactato no sangue e a capacidade vital em alunos de Aymara, se estas se medem em duas situações de altitude diferentes (nível do mar e acima de $3000 \mathrm{~m}$ de altitude)? 


\section{Objetivo geral}

Avaliar o rendimento físico e fisiológico em alunos de Aymara de 12 a 15 anos, residentes na Comuna de Putre, em duas situações geográfico-ambientais diferentes (planalto e nível do mar).

\section{Objetivos específicos}

a. Medir a potência anaeróbica em alunos de Aymara em idades de 12 a 15 anos, residentes na Comuna de Putre;

b. Medir antes e depois do esforço: o nível de ácido láctico no sangue; a potência anaeróbica; e a capacidade vital dos alunos em estudo, ao serem avaliados no planalto e no nível do mar;

c. Determinar a relação existente entre a altura geográfica, a potência anaeróbica, o nível de lactato no sangue e a capacidade vital dos alunos em estudo, ao serem avaliados no planalto e no nível do mar.

\section{Hipóteses}

- H1 - Os alunos em idades de 12 a 15 anos que habitam grandes altitudes (a $3.450 \mathrm{~m}$ ), ao serem medidos no nível do mar apresentam uma média maior de que sua capacidade vital e de sua potência anaeróbica, a uma probabilidade de $5 \%$.

- H2 - Os alunos em idades de 12 a 15 anos que habitam grandes altitudes (a $3.450 \mathrm{~m}$ ), ao serem medidos no nível do mar apresentam uma média menor de lactato no sangue depois de um esforço máximo, em nível do mar, a uma probabilidade de $5 \%$.

- H3 - Alunos que habitam altitude se associam positivamente nos rendimentos físico e fisiológico alcançados na capacidade vital, a potência anaeróbica e a produção de lactato em sangue, quando são medidos em nível de mar.

\section{Variáveis independentes}

a. Idade: período cronológico de vida, expresso em anos e meses;

b. Altura (altura do vértice): é a distância compreendida entre o vértice e o piso de um sujeito em posição anatômica, medida com um altímetro e expressa em metros;

c. Peso corporal: corresponde à massa corporal de um sujeito, medida em uma balança com precisão de 100g;

d. Altura do habitat (variável ambiental): corresponde à altura geográfica em que são residentes $(3.450 \mathrm{~m}$ e 30m);

e. Teste Wingate: teste ergométrico para medir a potência anaeróbica; f. Teste espirométrico: teste que permite medir a função pulmonar.

\section{Variáveis dependentes}

a. Potência anaeróbica: também chamada potência muscular de curta duração (PMCD); é a capacidade que tem o organismo humano para a obtenção de energia durante a realização de atividades físicas de curta duração (até $3 \mathrm{~min}$ ) e de alta intensidade, com uma frequência cardíaca entre 170 e 220 pulsações por minuto;

b. Nível de lactato no sangue: produto da degradação da glicose e, em forma especial, na célula muscular, durante a execução do exercício físico cuja duração foi de 30s e expressos em $\mathrm{mmol} . \mathrm{kg}^{-1}$;

c. Capacidade vital: é a maior quantidade de ar que pode se espirar depois de um esforço inspiratório máximo; é medido como um índice de função pulmonar, expresso em $\mathrm{mL}$.

\section{Variáveis intervenientes}

a. Nível de atividade ou mobilidade diária: corresponde à utilização do tempo livre (fora das horas de aula), em atividades físicas ou laborais;

b. Tempo de permanência nas diferentes altitudes: corresponde ao tempo de permanência nos lugares em onde se tomaram os testes (fora de seu hábitat).

\section{MATERIAIS E MÉTODOS}

presente estudo corresponde a uma investigação de desenho descritivo, transversal e comparativo para um grupo independente, com duas avaliações de teste e reteste, em níveis de altitude diferentes (variável ambiental). Foram definidas como variáveis independentes de estudo, principalmente: a altura do hábitat; o teste Wingate; e o teste de espirometria. Como variável dependente: a potência anaeróbica; o nível de lactato sanguíneo; e a capacidade vital.

\section{Seleção da amostra}

Dada a natureza da investigação, trabalhou-se com uma amostragem probabilística, utilizando-se o método de amostra simples ao acaso da população respectiva, a qual inclui alunos homens da etnia Aymara (com ambos sobrenomes Aymara), entre as idades de 12 e 15 anos, nascidos no planalto e com mais de três anos de residência estável no povoado de Putre, localizado acima de $3.000 \mathrm{~m}$ de altitude. A população existente corresponde a 42 alunos nas idades em estudo, da qual se tomou uma mostra ao acaso de 15 crianças que cumpriam com os critérios 
de inclusão. Dos alunos selecionados, dois deles não foram autorizados pelos pais, sendo ajustada a amostra para 13 crianças. Durante a aplicação do teste Wingate, porém, houve uma criança que desistiu de sua participação, reduzindo-se a amostra a 12 alunos.

A seleção da amostragem seguiu os seguintes procedimentos, os quais permitiram e asseguraram a posterior definição dos indivíduos que confirmaram a amostra:

a. Prévio à iniciação do estudo, se realizou uma entrevista pessoal com o Prefeito da llustre Municipalidade de Putre, a quem se entregou uma carta com os antecedentes e detalhes do estudo a ser realizado, obtendo-se desta maneira a autorização para executar a investigação. Igual gestão se realizou com o Diretor do Liceu C da Comuna de Putre;

b. Obtidas ambas as autorizações, analisou-se com - Sr. Luis Romero, professor de Educação Física do Liceu de Putre, os detalhes pertinentes à tomada da amostra, tanto em Putre como em Arica;

c. Foi realizada uma reunião com os alunos Aymara, onde foram informados sobre o que consistia o estudo, e thes foi entregue uma carta informativa para os pais ou responsáveis, com a finalidade de que estes autorizassem com sua assinatura a participação de seu filho no estudo.

\section{Definição e operacionalização das variáveis de estudo}

Os sujeitos selecionados, de ambos os grupos em estudo, foram submetidos às diferentes medições programadas, tanto em altitude como em nível do mar.

\section{Instrumentos}

Os instrumentos utilizados nas medições realizadas foram os seguintes:

a. Uma balança médica, com precisão de 100g;

b. Um altímetro, com precisão de $1 \mathrm{~cm}$;

c. Dois cronômetros digitais com memórias e precisão de 0,01s;

d. Um cicloergômetro mecânico (Monark), modificado;

e. Um odômetro conta-giros;

f. Um espirômetro computadorizado (Pony);

g. Um fotômetro analisador de lactato.

\section{Protocolo das medições realizadas}

Aos alunos selecionados para o estudo, foram aplicadas as seguintes medições:

a. Peso: o peso da massa corporal se determinou com os pés descalços e com vestimenta de ginástica (camiseta, short); b. Altura: a altura do vértice, medido com o pé descalço;

c. Capacidade Vital: medida mediante uma expiração forçada máxima com prévia inspiração máxima, utilizando-se o espirômetro.

protocolo utilizado foi:

- Antes de iniciar o teste, o sujeito a ser avaliado colocou uma pinça nas fossas nasais para impedir que se produzisse escape de ar ao realizar a expiração;

- Posteriormente, o avaliado ficou de pé contra o espirômetro, e depois realizou, como preparação, duas inspirações máximas prévias;

- Seguidamente efetuou uma inspiração até a capacidade pulmonar total (CPT), e depois realizou um esforço expiratório máximo (soprar a maior quantidade de ar possível, através da boquinha do espirômetro) ( para cada sujeito avaliado foi utilizada uma boquinha nova). Esta ação se realizou três vezes, tomando-se o valor da melhor. Em cada uma das medições utilizou-se animação com insistência para que o sujeito seguisse soprando o mais que pudesse.

d. A potência anaeróbica (PA) de cada criança se mediu mediante a aplicação do Teste de Wingate, usando o cicloergômetro junto com o odômetro.

A PA, para cada criança controlada, se quantificou pela seguinte fórmula:

$$
P A=\frac{\pi \times 0,5 \times 10,152 \times \text { carga } \times r p m}{12}
$$

onde

$\pi=3,1416$

carga $=$ peso corporal $\times$ 0,075 (o valor 0,075 é o fator que se usa no ergômetro Monark)

rpm = média de revoluções por minuto, por cada período de $5 \mathrm{~s}$

os demais valores que aparecem na fórmula são constantes

Fazendo-se as substituições das constantes na fórmula, obtém-se o seguinte indicador para a potência anaeróbica:

$\mathrm{PA}=0,0997 \times$ peso $\times \mathrm{rpm}$ [unidade quilogrâmetro $(\mathrm{kgm})]$.

\section{Situação experimental}

A situação experimental a qual foram submetidos os alunos considerou uma primeira avaliação correspondente a seu hábitat (Putre). Este se realizou três dias antes da avaliação correspondente em nível de mar. 
A operacionalização do protocolo dos testes foi a seguinte:

- Tomar a frequência cardíaca e pressão arterial em repouso.

- A carga a mobilizar foi igual a 0,075 vezes o peso corporal de indivíduo avaliado $(0,075 *$ peso corporal).

- Uma vez situado o avaliado no cicloergômetro, se determinou a altura do selim de maneira que o joelho do sujeito se encontrasse quase estendido, quando os pedais ficam na sua posição inferior.

- Antes da realização do teste, o avaliado realizou um aquecimento no cicloergômetro durante $3 \mathrm{~min}$ a $4 \mathrm{~min}$ a uma velocidade que elevou sua frequência cardíaca para 150 a 160 batimentos por minuto. Este aquecimento foi realizado com algumas acelerações, ou sprints máximos intermediários, com duração entre 4 s e $5 \mathrm{~s}$, com a finalidade de sensibilizar o sujeito com o teste a realizar.

- Terminado o aquecimento, o avaliado descansou $2 \mathrm{~min}$.

- Após um sinal, deu-se por iniciado o teste, com o sujeito tendo que pedalar na maior velocidade possível durante 30s.
- A carga do cicloergômetro se realizou durante os primeiros $2 \mathrm{~s}$ a $4 \mathrm{~s}$ de iniciado o teste.

- No preciso momento em que se alcançou a carga ótima, iniciou-se a contagem da pedalada a cada $5 \mathrm{~s}$.

- A conta das pedaladas se registrou a cada 5s, durante os 30s que durou o teste. Este registro se realizou mediante a utilização de um ciclocomputador (Catey) com cadência (modelo Astrale CC-CD100 N), que contou as revoluções, além de dois ajudantes. Um deles contou em voz alta a contabilidade dos giros de pedal a cada 5 s registrados no cadenciômetro. O segundo observador anotou na planilha os resultados a cada $5 \mathrm{~s}$.

- Uma vez terminado o teste (os 30s de esforço), se tomou a frequência cardíaca e a pressão arterial. $\bigcirc$ avaliado seguiu pedalando durante mais $2 \mathrm{~min}$ com uma carga leve, com a finalidade de voltar à calma.

- $\quad$ nível de lactato no sangue foi medido através de uma amostra de $3 \mathrm{~mL}$ de sangue, obtida mediante uma punção venosa antes e depois do esforço (a amostra foi tomada por um tecnólogo médico especializado). Para impedir que o sangue se co-

Tabela 2 - Média e desvio padrão da composição corporal dos sujeitos em estudo

\begin{tabular}{lcccccccc}
\hline idade & peso & altura & \%MG & \%P. Ósseo & \%P. Resid & \%MMA & K.MMA \\
\hline 13 & 43,07 & 1,51 & 22,31 & 28,69 & 24,90 & 24,10 & 10,38 \\
1.07 & 7,50 & 0,07 & 5,05 & 2,82 & 0,00 & 4,13 & \\
\hline
\end{tabular}

\% MG: porcentagem de massa gorda; \% P. Ósseo: percentagem de peso ósseo; \%P. Resid: percentagem de peso residual; \%MMA: porcentagem de massa muscular ativa;

K.MMA:kg de massa muscular ativa;

Tabela 3 - Resultados de média e desvio padrão do teste Wingate em crianças Aymara de Putre, medido em duas situações geográficas diferentes

\begin{tabular}{cccccccccccccc}
\hline & idade & peso & altura & carga & $0-5$ & $5-10$ & $10-15$ & $15-20$ & $20-25$ & $25-30$ & $\begin{array}{c}\text { rotações acu- } \\
\text { mulativas }\end{array}$ & $\begin{array}{c}\text { rotações a } \\
\text { cada 5s }\end{array}$ \\
\hline \multirow{2}{*}{ Arica } & 13,1 & 43,8 & 1,5 & 3,3 & 6,58 & 8,82 & 7,84 & 7,44 & 6,69 & 6,28 & 40,7 & 7 \\
& 1,1 & 7,4 & 0,1 & 0,6 & 0,83 & 1,27 & 1,25 & 1,01 & 0,98 & 1,32 & 4,6 & 1 \\
\multirow{2}{*}{ Putre } & 13,1 & 43,8 & 1,5 & 3,3 & 6,6 & 8,6 & 6,8 & 6,6 & 6,1 & 5,8 & 38,0 & 6 \\
& 1,1 & 7,4 & 0,1 & 0,6 & 1,2 & 1,8 & 1,4 & 1,4 & 1,1 & 1,1 & 6,1 & 1 \\
\hline
\end{tabular}

Tabela 4 - Média e desvio padrão da potência máxima anaeróbica e seus derivados alcançados por crianças de Putre

\begin{tabular}{lcccc}
\hline & PMA & PMR & PMEA & PMER \\
\cline { 2 - 5 } & (W) & $\left({\left.\mathrm{W} . \mathrm{kg}^{-1}\right)}^{-1}\right.$ & $(\mathrm{W})$ & $\left(\mathrm{Wg}^{-1}\right)$ \\
\hline \multirow{2}{*}{ Arica } & 337.1 & 7.6 & 282.6 & 6.4 \\
& 93.3 & 1.3 & 68.0 & 0.8 \\
\multirow{2}{*}{ Putre } & 318.8 & 7.1 & 247.0 & 5.6 \\
& 110.8 & 1.6 & 67.8 & 0.9 \\
\hline
\end{tabular}

PMA: potência anaeróbica máxima absoluta durante 5s;

PMR: potência máxima relativa durante 5 s;

PMEA: potência média máxima absoluta durante 30s;

PMER: potência média relativa durante 30 s. 
agulasse, as amostras obtidas foram tratadas com o anticoagulante EDTA fluorado, impedindo desta maneira a glicólise dos glóbulos vermelhos. Posteriormente as amostras foram centrifugadas com a finalidade de separar o plasma dos elementos figurados do sangue (glóbulos vermelhos, glóbulos brancos e plaquetas).

- A determinação do lactato se realizou através do método calorimétrico, aplicando ao plasma um kit comercial de lactato, que possui um padrão, um controle e um reativo cromógeno, que produz cor com diferente intensidade, a qual depende da concentração de lactato existente na mostra. $\bigcirc$ padrão, o controle e amostra desconhecida se misturaram com o reativo cromógeno, se encubando por $10 \mathrm{~min}$ em banho-maria a $37^{\circ} \mathrm{C}$. Posteriormente, as amostras foram aspiradas uma a uma por um fotômetro, o qual deu o resultado da medição em mmol por litro de amostra.

\section{Tratamento dos dados}

Utilizaram-se estatísticas descritivas de medidas de tendência central e de dispersão. Além disso, para responder as hipóteses colocadas, foram aplicadas estatísticas inferenciais paramétricas para amostras independentes (intragrupo) e para dados de medidas temporárias diferentes de uma mesma amostra, assim como também a análise de correlação de Pearson. $\bigcirc$ objetivo da análise foi determinar a existência ou não de diferenças significativas nas médias verdadeiras, por aluno, para as variáveis que caracterizam o rendimento fisiológico deles, ao realizar um esforço ou atividade física em altitude e em nível do mar. Para isso, se utilizou o teste " $t$ " de Student e o teste de categorias atribuídas de Wilcoxon, para situações em que os dados se apresentam muito agrupados, a qual não é sustentável a suposição de normalidade.

\section{RESULTADOS}

Este trabalho de pesquisa foi orientado para avaliar o rendimento físico e fisiológico de alunos de ascendência Aymara, com idades entre 12 e 15 anos, residentes na localidade de Putre, a $3.450 \mathrm{~m}$ acima do nível do mar.

$\mathrm{Na}$ Tabela 2 se apresentam os resultados obtidos das medições antropométricas realizadas nos alunos em estudo. Nela se podem observar as características da composição corporal (porcentagem de massa gordura, massa óssea, peso residual e massa muscular) das crianças de Aymara.

Os resultados conseguidos na aplicação do teste Wingate nos alunos de Aymara que habitam Putre se encontram na Tabela 3. Nela, se pode apreciar a carga média aplicada ao grupo de crianças de Aymara, assim como observar a cadência das revoluções de pedal realizada a cada $5 \mathrm{~s}$, durante os 30s. Neste caso (tanto em altitude como no nível de mar), o pico máximo se obteve entre 5 s e 10s, para, posteriormente, ir decrescendo paulatinamente a cada 5s. Não obstante, ao nível do mar se aprecia uma leve melhora em relação ao rendimento alcançado em Putre. Mesmo assim, a diferença conseguida no momento do pico em nível de mar só chega a 2,49\% acima do alcançado em Putre.

Quanto à potência anaeróbica máxima absoluta durante 5s (PMA), conseguida pelos alunos em estudo em ambas as medições - altitude (Putre) e nível do mar (Arica) -, apresentadas na Tabela 4, pode-se manifestar que o rendimento alcançado em Arica, apresenta um aumento de 5,6\% em relação ao conseguido em Putre. Quanto à potência anaeróbica máxima relativa durante 5s (PMR), não se observa uma diferença significativa. No entanto, a potência média máxima absoluta durante 30 s (PMEA) apresenta um aumento de 36 watts, equivalente a $14,5 \%$

Tabela 5 - Média e desvio padrão de potência anaeróbica de alunos de Putre medidos em duas situações de altitudes diferentes

\begin{tabular}{lccccc}
\hline & peso $(\mathrm{kg})$ & Putre $(\mathrm{rpm})$ & Putre $(\mathrm{PA} \mathrm{kgm})$ & Arica (rpm) & Arica (PA kgm) \\
\hline media & 43,83 & 7,13 & 31,3 & 7,44 & 32,71 \\
desvio padrão & 7,38 & 1,13 & 8,81 & 0,97 & 8,23 \\
\hline
\end{tabular}

PA: potência anaeróbica; rpm: rotações por minuto

Tabela 6 - Nível de lactato no sangue, resultados da aplicação do teste Wingate em duas situações geográficas diferentes

\begin{tabular}{lccc}
\hline & pré-teste & pós-teste & diferença \\
\hline \multirow{2}{*}{ Arica - nível do mar } & 2,38 & 7,33 & 4,95 \\
& 0,78 & 1,73 & 1,61 \\
Putre - altitude & 1,50 & 11,21 & 8,26 \\
& 0,40 & 3,71 & 2,62 \\
\hline
\end{tabular}


Tabela 7 - Resultados de média e desvio padrão de lactato no sangue alcançado por alunos de Aymara no teste de Wingate medidos em Putre (altitude) e Arica (nível do mar)

\begin{tabular}{ccccccc}
\hline alunos Aymara $\mathrm{n}=12$ & Putre & Arica & diferença Arica - Putre & $t_{\circ}$ & $t_{c}$ & $\mathrm{gl}$ \\
\hline média & 8,26 & 5,66 & 2,62 & $3,42 *$ & 1,80 & 11 \\
desvio padrão & 2,62 & 1,61 & 2,65 & & & \\
\hline
\end{tabular}

${ }^{*} p<0,05$

Tabela 8 - Espirometria em alunos de Putre versus espirometria de Arica (média e desvio padrão)

\begin{tabular}{ccc}
\hline & capacidade vital (média \pm desvio padrão) & diferença \\
\hline Putre & Arica & $471,1 \pm 9,3$ \\
$2766,7 \pm 365,8$ & $3237,8 \pm 356,5$ & 47,5 \\
\hline
\end{tabular}

Tabela 9 - Resultados de média e desvio padrão de alunos de Aymara no teste de espirometria medido em Putre (altitude) e Arica (nível do mar)

\begin{tabular}{lcccccc}
\hline alunos Aymara $(\mathrm{n}=12)$ & Putre & Arica & diferença Arica - Putre & $t_{\circ}$ & $t_{c}$ & $g l$ \\
\hline média & 2766,7 & 3237,8 & 470,8 & & & \\
desvio padrão & 365,8 & 356,5 & 207,5 & $7,86 *$ & 2,20 & 11 \\
\hline
\end{tabular}

$* p<0,05$

Tabela 10 - Correlação entre as variáveis em estudo com relação a duas situações geográficas diferentes

\begin{tabular}{lcccc}
\hline Aymaras & \multicolumn{2}{c}{ em Putre } & \multicolumn{2}{c}{ em Arica } \\
\hline & CV & lactato & CV & lactato \\
p. anaeróbica & 0,46 & 0.21 & 0,65 & 0,05 \\
lactato & $-0,03$ & & $-0,01$ & \\
\hline
\end{tabular}

\section{Potência anaeróbica}

No que diz respeito à PA, na análise dos resultados conseguidos pelos alunos de Putre, não se observou diferença significativa entre ambos os rendimentos, isto é, não se apresentou uma melhoria de seu PA ao serem medidos ao nível do mar (Tabela 5).

\section{Nível de lactato}

O nível de lactato no sangue (mmoles por litro) de cada aluno se mediu de acordo com um protocolo que considera a análise com uma amostra de $3 \mathrm{~mL}$ de sangue, usando o método calorimétrico e um fotômetro analisador de lactato. As medições foram feitas (segundo o protocolo), antes e depois do esforço realizado pelo aluno.

A análise estatística se fez com base nas medições da diferença entre o nível de lactato, controlado na situação de repouso do aluno, com o nível controlado depois que o aluno realizou o esforço. Ou seja, esta diferença mede o aumento no nível de lactato devido ao esforço realizado pelo aluno.

Os níveis de lactato no sangue, medidos pré-teste e pós-teste, são expostos na Tabela 6 . No caso das crianças ao nível do mar, se pode ver que em ambas as situações geográficas o lactato sanguíneo préteste é normal. No entanto, depois que realizado o esforço, ocorre um aumento para $4,35 \mathrm{mmol}^{-L^{-1}}$ ao nível de mar e 4,52 mmol. $L^{-1}$ a $3.450 \mathrm{~m}$ de altitude, equivalente a um aumento de 74,48\% e 78,74\%, respectivamente.

Ao observar as diferenças $(\Delta)$ alcançadas pelos alunos de Putre, entre o pré-teste e pós-teste, pode-se manifestar que sua medição em Putre apresentou um aumento de $73,68 \%$ de lactato em sangue, com relação aos níveis apresentado no pré-teste. Em contrapartida, ao nível do mar esta diferença pré-teste e pós-teste alcança 67,53\%. Neste caso, a evidência estatística baseada na teste " $t$ " comprova o fato de que, em média, os alunos de Putre, que habitam acima de $3.000 \mathrm{~m}$, ao ser submetidos a esforços máximos ao nível de mar diminuem significativamente seus níveis de lactato no sangue em $5 \%$.

Com relação à evidência estatística apresentada na Tabela 7, baseada no teste " $t$ ", com um $t_{0}$ de 3,42, se pode manifestar que a média dos alunos de Aymara, ao serem submetidos a esforços máximos, mudam significativamente $(p>0,05)$ seu nível de lactato no sangue quando se deslocam de Putre para Arica, ao nível do mar.

\section{Capacidade vital (CV)}

Nesta oportunidade, a CV foi medida com o espirômetro. $\bigcirc$ protocolo consistiu em medir a quantidade máxima de ar em uma das três expirações forçadas, com prévia inspiração em cada uma delas.

As medições realizadas da espirometria, junto com as diferenças e o ranking das ditas diferenças, são descritas na Tabela 8.

Os resultados destas medições nos alunos em estudo apresentaram, em seu habitat, um nível de CV baixa em 
relação aos valores preditos $(3.952 \mathrm{~mL})$, segundo Baldwin (1996). No entanto, ao serem avaliados ao nível do mar, estes apresentaram um aumento de 14,54\%, diferença que é significativa $(p<0,05)$.

Os resultados brutos do teste de espirometria são sintetizados na Tabela 9, a qual apresenta média e desvio padrão da amostra de crianças Aymara que habitam em altitude, acima de $3.000 \mathrm{~m}$. Aplicando o teste " $t$ " a estes dados, eles mostram uma diferença significativa para $t_{0}=7,86$, com um $p<0,05$, o que evidência que, em média, as crianças aumentam significativamente sua capacidade vital ao nível do mar.

\section{Correlações}

Em relação, ao grau de afinidade entre os resultados conseguidos pelas crianças em estudo, nas diferentes variáveis avaliadas e em duas situações geográficas diferentes, podemos manifestar que, entre os rendimentos alcançados em PA e CV, o nível da correlação é boa. No entanto, a afinidade atingida no nível de lactato no sangue é muito fraca.

Ao realizar as correlações respectivas entre as variáveis em estudo, somente em altitude ou somente ao nível do mar, se pode ver nos resultados apresentados na Tabela 10 que, tanto em Putre como em Arica, não há afinidade entre a CV e o nível de lactato no sangue. Situação Similar se observa na correlação entre CV e PA.

\section{DISCUSSÃO}

Os resultados obtidos nas variáveis medidas em relação às hipóteses colocadas ao início do estudo, nos assinalam o seguinte:

Com relação à Hipótese 1 se pode assinalar que se aceita a hipótese alternativa, confirmando que as crianças que habitam em altitude melhoram o nível de sua CV ao serem transportadas para o nível do mar. No entanto, apesar desta melhoria em seu CV, estas crianças só apresentam um aumento de 3,54\% na sua potência anaeróbica ao serem avaliadas ao nível do mar, o que não é significativo $(p>0,05)$. Neste caso, produz-se uma associação muito fraca entre a melhoria da CV e a PA.

A evidência estatística baseada no teste " $t$ " prova que, na média, os alunos de Putre, que vivem a $3.450 \mathrm{~m}$ de altitude, não aumentariam significativamente sua potência anaeróbica quando se transladassem ao nível do mar.

Esta baixa melhoria da PA é factível de ser atribuída ao fato de que estas crianças, que têm uma vida muito sedentária devido ao tempo de mobilidade diária, ou seja, as atividades físicas recreativas realizadas fora das horas de aula são poucas, além da pouca possibilidade de deslocamento urbano, já que a localidade de Putre se encontra em uma depressão e o perímetro do povoado não tem mais de $5.500 \mathrm{~m}$. A isto se deve somar o feito de que, apesar de sua atividade diária se iniciar, em média, às 7 h30min, esta termina, mais menos, às $19 \mathrm{~h}$, pois escurece mais cedo e a temperatura fica abaixo de $-10^{\circ} \mathrm{C}$.

No que se refere à hipótese $H 2$, esta é aceita, iá que os resultados baseados no teste " $t$ " provam que, na média, os alunos de Putre, que vivem a $3.450 \mathrm{~m}$ de altitude, ao serem submetidos a esforço de caráter anaeróbico, diminuem significativamente seu nível de lactato no sangue quando se deslocam desde Putre até Arica, que é uma cidade situada ao nível do mar.

Com relação à Hipótese $\mathrm{H} 3$, que manifesta que os alunos que habitam em altitude se associam positivamente nos rendimentos físico e fisiológico alcançados na $\mathrm{CV}$, na potência anaeróbica e na produção de lactato no sangue, quando são medidos ao nível do mar. Neste caso, a hipótese é rejeitada, iá que os índices de correlação obtidos entre as diferentes variáveis em estudo, são baixos e muito fracos.

\section{REFERÊNCIAS}

1. Platonov VN, Bulatova MM. Entrenamiento en condiciones extremas. Barcelona: Paidotribo; 1998

2. Santolaya BR, Salazar CL, Sandoval MN, Santolaya CR, Alfaro TR. Nuestra experiencia en residentes permanentes de altura: calidad de la aclimatación. Centro de Investigaciones Ecobiológicas y Médicas de Altura (CIEMA). Odelco. Chile;1993.

3. Astrand PO, Rodahl K. Fisiología del trabajo físico. $3^{a}$ ed. Madrid: Panamericana; 1992

4. Fellmann N, Coudert J, Spielvogel H, Bedu M, Obert P, Falgairette G, et al. La salud de residente de los niños a la altitud alta en Bolivia. Int J Sports Med. 1992;13 Suppl 1:S92-5.

5. Blimkie CJ, Roche P, Bar-Or O. Concept of anaerobic to aerobic power ratio in pediatric health and disease. Em: Rutenfranz J (editor). Children and Exercise XII. Champaign, II: Human Kinetics; 1986.

6. Bouchard C, Taylor AW, Simoneau J-A, Dulac S. Evaluación de la potencia y capacidad anaeróbica. Barcelona: Paidotribo; 2006.

7. Van Praagh E, Doré Eric. Potencia muscular de corta duración durante e crecimiento y la maduración (Resumen). PubliCE Premium; 2004.

8. Dawson $\mathrm{AH}$. Espirometria, pruebas de funcionamiento pulmonar indicaciones e Interpretación. Capitulo II. Orlando: 1985.

9. Fisher AG, Vehrs Pat R. Test y pruebas físicas. $2^{a}$ ed. Barcelona: Edit; 1999.

10. López EJM, Sánchez MLZ. Elementos básicos de control fisiológico de alumno de Educación Física: $\mathrm{Vo}_{2 \text { máx }}$ capacidad vital y aeróbica. Efdeportes. com [serial na internet]. 2003 jul [citado em 2008 ago]; 9(62): [cerca de 10 telas]. Disponivel em: www.efdeportes.com/efd62/vo2.htm.

Recebido: 22/08/08 - Aceito: 13/12/08 